\title{
IMPROVE YOUR BONE AND MUSCLE TONE : EVALUATION OF A STRENGTH TRAINING PROGRAM ON THE CENTRAL COAST OF NSW
}

\section{Christine Edwards and Gina Stuart \\ Health Promotion Unit \\ Central Coast Area Health Service}

Ageing is a complex process involving changes in physiological and psychological functioning, which often results in decreased functional capacity, loss of independence, and poor quality of life. ${ }^{1}$

Through improvements in muscular strength and endurance, strength training can reduce sedentariness, increase levels of incidental and planned physical activity, and improve ability to carry out activities of daily living. In doing so strength training can contribute to an improvement in the overall health and wellbeing of older adults. $^{2}$

Strength training involves applying a resistance or load to a muscle-generating force. To achieve increases in strength, the load must be progressively increased, and be perceived by the individual as 'somewhat hard' to 'hard' ${ }^{3,4,5}$ Fitness centres have appropriate equipment and personnel, and are well-placed to oversee safe and effective strength training for older adults.

Private fitness centres on the Central Coast have demonstrated their commitment to older residents by collaborating with the Health Promotion Unit of the Central Coast Area Health Service, in providing popular, successful, and high quality gentle exercise programs for older adults. Provision of strength training programs offers fitness centres an opportunity to build on existing gentle exercise programs, thus providing a wider variety of activities for older adults. This article describes an evaluation of the first 12 months of the Improve Your Bone and Muscle Tone program implemented in private fitness centres on the Central Coast of NSW in October, 2000.

\section{METHODS}

The four objectives of the Improve Your Bone and Muscle Tone program were to:

- increase the proportion of providers offering strength training programs;

- increase the number of older Central Coast residents participating in strength training programs;

- increase participants' strength, fitness, physicalactivity levels, and confidence in carrying out daily activites;

- measure the increase in strength of participants through a 12-month audit of fitness centre records.
Several strategies were used by the Health Promotion Unit to encourage the local fitness industry to provide strengthtraining programs specifically for older people. These strategies included:

- small grants offered to fitness centres to initiate the Improve Your Bone and Muscle Tone program;

- specialised training workshops for staff and managers of participating centres;

- providing training guidelines, a range of promotional resources, and ongoing newspaper advertising, for participating centres.

In the course of evaluating the Improve Your Bone and Muscle Tone program:

- participating centres provided monthly data on the number of male and female participants and class frequency, as well as a six-monthly written progress report;

- all participants were asked to complete a baseline questionnaire on commencement of the program, which included questions on current physical activity levels, perceived fitness and strength, and satisfaction with initial instruction from fitness centre staff;

- six months after the classes commenced, consenting participants completed a follow-up telephone questionnaire to ascertain their current level of participation, length of attendance, reason for stopping and/or intention to continue, and confidence in carrying out daily activities.

Physical activity levels, perceived fitness and strength, and satisfaction with instruction from staff were reassessed twelve months after implementation of the Improve Your Bone and Muscle Tone program. Fitness centre records were used to objectively measure strength gains made. Exercise type, weight lifted, and number of sessions attended were recorded.

\section{RESULTS}

Prior to the launch of the program in October 2000, there were no specific strength training programs for older people offered on the Central Coast. Since then, 50 per cent of Central Coast fitness centres have successfully established, maintained, or expanded the Improve Your Bone and Muscle Tone program.

A total of 19 strength-training classes are now available at five fitness centres. Currently, there are a total of 650 attendances per month, which has increased from 120 


\section{FIGURE 1}

PERCEIVED STRENGTH OF PARTICIPANTS AT INITIAL VISIT AND 6 MONTHS AFTER COMMENCING THE PROGRAM

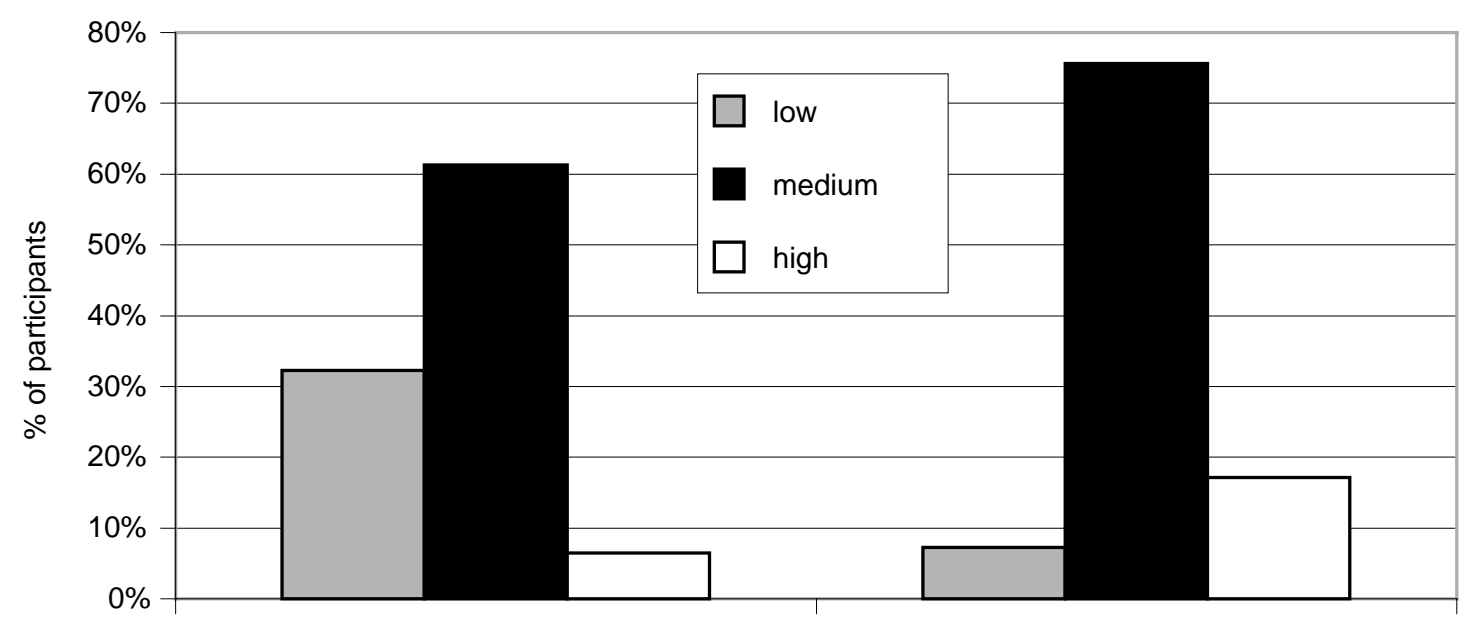

initial visit

$6 m$ th

\section{FIGURE 2}

PERCEIVED FITNESS OF PARTICIPANTS AT INITIAL VISIT AND 6 MONTHS AFTER COMMENCING THE PROGRAM

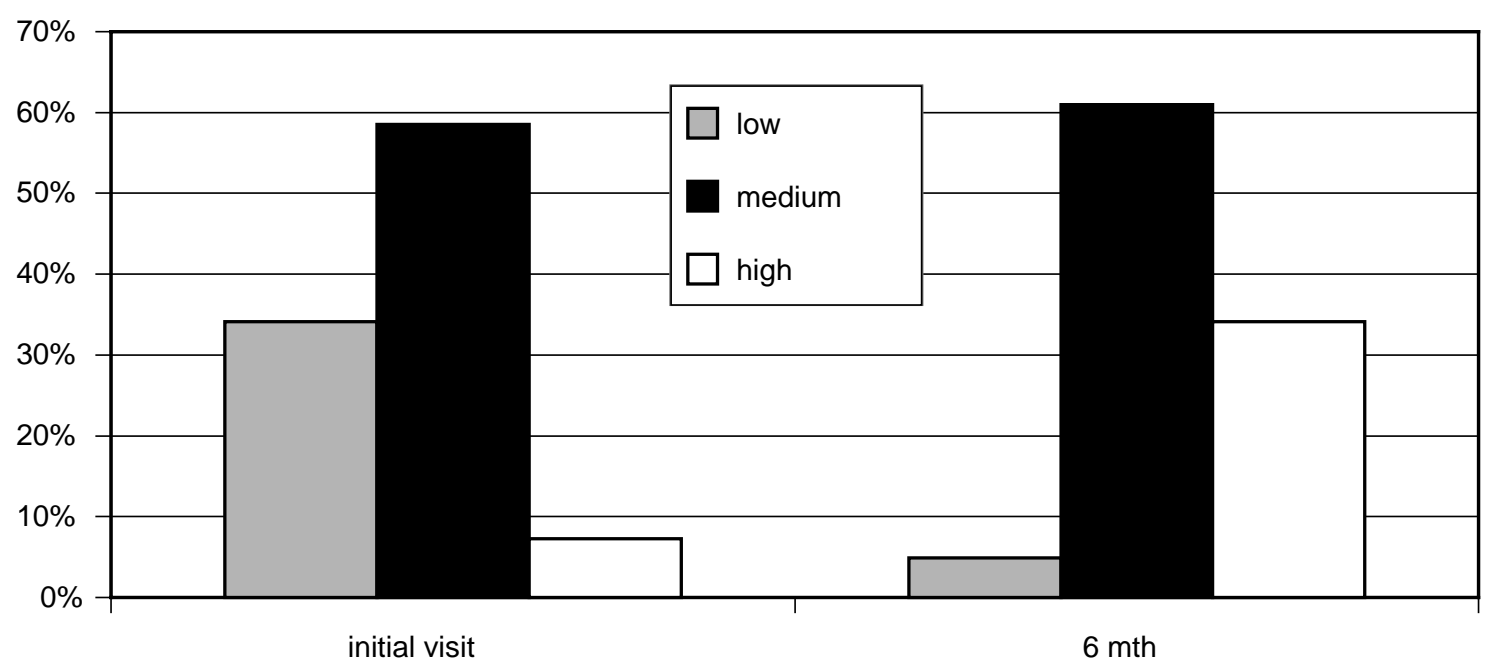

\section{TABLE 1}

MEAN WEIGHT LIFTED BY PARTICIPANTS AT FIRST AND LAST VISITS FOR EACH EXERCISE

\begin{tabular}{|lcccc|}
\hline Type of exercise & $\begin{array}{c}\text { Mean weight lifted } \\
\text { at first visit }\end{array}$ & $\begin{array}{c}\text { Mean weight lifted } \\
\text { at last visit }\end{array}$ & $\begin{array}{c}\text { Mean } \\
\text { difference }\end{array}$ & Sample size \\
\hline Leg press & $18.4 \mathrm{kgs}$ & $27.4 \mathrm{kgs}$ & $9 \mathrm{kgs}$ & 123 \\
Chest press & $11.7 \mathrm{kgs}$ & $17.6 \mathrm{kgs}$ & $5.8 \mathrm{kgs}$ & 127 \\
Lat pull-down & $17.8 \mathrm{kgs}$ & $23.28 \mathrm{kgs}$ & $5.4 \mathrm{kgs}$ & $<0.001$ \\
Shoulder press & $6 \mathrm{kgs}$ & $8.7 \mathrm{kgs}$ & $2.6 \mathrm{kgs}$ & $<.001$ \\
Seated row & $14.8 \mathrm{kgs}$ & $21.7 \mathrm{kgs}$ & $6.9 \mathrm{kgs}$ & $<0.001$ \\
\hline
\end{tabular}




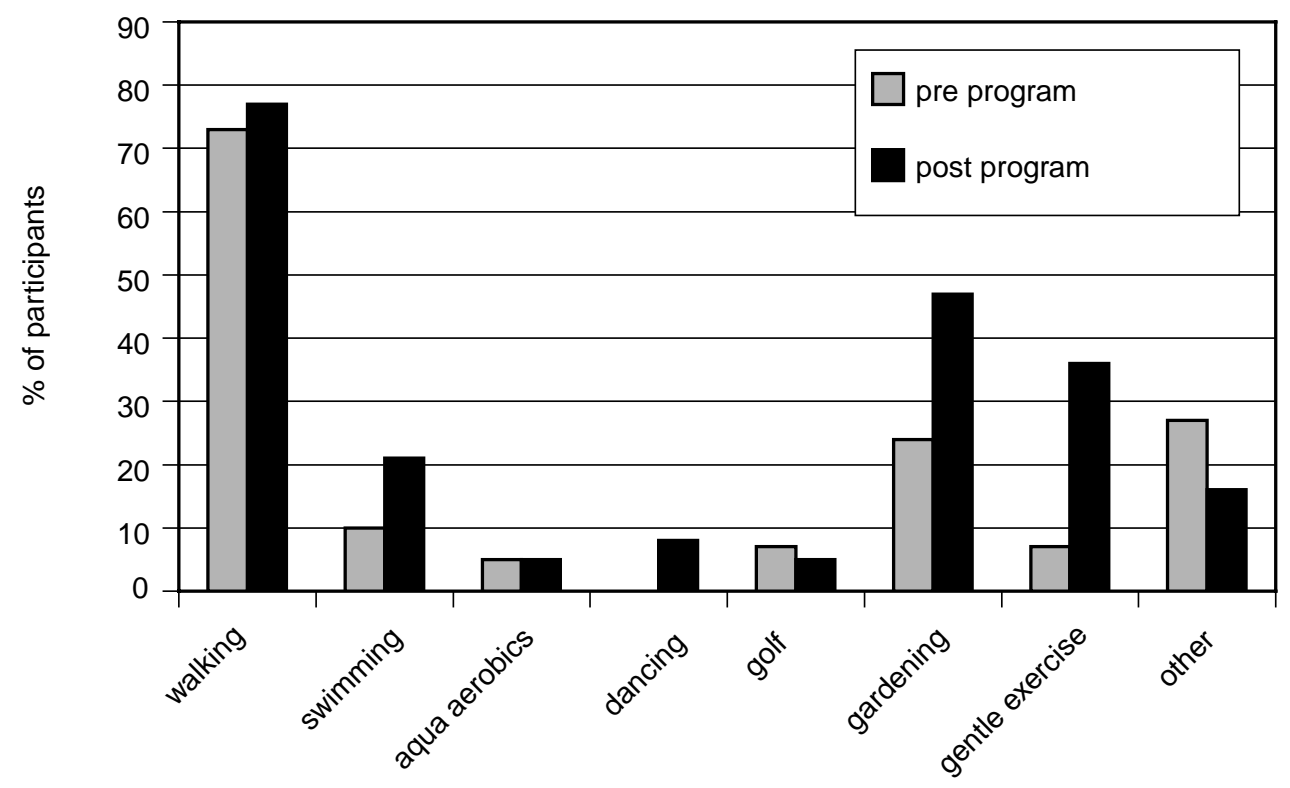

attendances per month since December 2000. Seventy per cent of participants are women and 30 per cent are men, with a mean age of 65 years.

All sixty-two participants who attended the initial session in the first four fitness centres that adopted the Improve Your Bone and Muscle Tone program completed the baseline questionnaire. Of these, 55 agreed to be followed up at six months, and 41 were able to be contacted by telephone at six months. Of these 41, 66 per cent were still participating. Only one person cited that they found the cost prohibitive, and another that they did not enjoy the program. Ninety-three per cent of participants reported that instructors were 'very helpful' initially, with the same percentage stating instructors remained 'very helpful' after six months participation. Forty-two percent of participants rated their strength level as higher after six months participation (Figure 1). Fifty-six percent of participants rated their fitness level as higher after six months participation (Figure 2).

Sixty-three per cent indicated that strength training had given them either moderately more confidence (30 per cent) or a lot more confidence (33 per cent) in carrying out daily activities such as shopping, climbing stairs, other exercise, gardening, or rising from a chair.

Thirty-six per cent of participants were 'insufficiently active' according to Active Australia Guidelines at the time they commenced the program. ${ }^{6}$ This had decreased to 22 per cent after six months participation. Figure 3 illustrates involvement in other types of physical activity, before starting the Improve Your Bone and Muscle Tone program, and after six months in the program.

Participants' records from four Improve Your Bone and Muscle Tone fitness centres were audited 12 months after the commencement of the program. Only those participants who had been strength training for three sessions or more were included in the sample. This comprised 137 participants.

For each participant, weights lifted (in kilograms) at the first and last visits were recorded for each type of exercise. Differences in weight lifted between first and last visits were calculated. Students' T-tests were carried out to ascertain whether participants showed significant increases in the amount of weight they could lift.

Significant increases in amount of weight lifted were found in all types of strength training exercise (Table 1).

\section{DISCUSSION}

The Improve Your Bone and Muscle Tone program met all four of its objectives. Five of the 10 Central Coast fitness centres provided 16 strength training classes for older people, with 650 attendances per month. Most participants were satisfied with the instruction they received, and reported a perceived increase in strength and fitness. Records of weights lifted confirmed participants increase in strength. Almost all participants reported feeling more confident in performing daily activities after completing the Improve Your Bone and Muscle Tone program. 
A 66 per cent retention rate of participants was considered to be reasonable, given that most of those who had dropped out reported intending to return to the program. Rapport with instructors, the camaraderie of one's own age group, measurable feedback on progress, and the self-paced and individualised nature of the program, appear to contribute to enjoyment of strength training.

Two-thirds of participants were sufficiently active before commencing the program and the increase in the percentage of sufficiently active participants was small. While the program may be 'preaching to the converted', it is worth noting that strength training provides specific benefits for older people that cannot be gained through the other forms of exercise reported. ${ }^{7,8,9}$ No participants were involved in specific strength training prior to the commencement of the program, though many were undertaking some form of weight-bearing exercise.

Nearly one-third of the participants in the Improve Your Bone and Muscle Tone program were men. Gentle exercise programs conducted for the same age group by private fitness centres in cooperation with the Health Promotion Unit have consisted of less than 10 per cent males. This is an important positive outcome for the program, because it represents a feasible population health strategy to increase physical activity among older men.

\section{CONCLUSION}

The Improve Your Bone and Muscle Tone program has been effectively established and maintained by the local fitness industry in collaboration with the Health Promotion Unit of the Central Coast Area Health Service. It is a good example of a sustainable physical activity program for older people, which has resulted in significant positive outcomes for its participants. The next 12 months will see more centres join in providing strength training for older people. A new aspect will be to publicise an 'easy start' component for people newly engaging in physical activity or lacking confidence in this environment.
An ongoing challenge is ensuring that fitness centre staff are adequately prepared for providing this program for an audience of older people who have not historically been customers. Development of guidelines for the State, in association with Fitness NSW, will be an important step.

For further information on Improve Your Bone and Muscle Tone, contact Gina Stuart by telephone on (02) 4349 4813; by fax on (02) 4349 4866; or by email at gstuart@doh.health.nsw.gov.au.

\section{REFERENCES}

1. American College of Sports Medicine, Position Stand 1998. Exercise \& Physical Activity for Older Adults. Med Sci Sports 1998; 30(6):992-1008.

2. Rogers MA, Evans WJ. Changes in skeletal muscle with ageing: effects on exercise training. Exer Sport Sci Rev 1993; 21: $65-102$.

3. Egger G, Champion N, and Bolton A. 1998. Exercise Training for Strength and Resistance. The Fitness Leaders, Handbook-4th Edition. Sydney: Simon and Schuster, 1998.

4. Evans WJ. Exercise Training Guidelines for the Elderly. Med Sci Sports Exercise 1999; 31 (1): 12-7.

5. Feigenbaum MS, Pollock ML. Prescription of resistance training for health and disease. Med Sci Sports Exerc 1999; 31(1): 38-45.

6. Active Australia. Guide for professionals promoting physical activity as part of the Active Australia-International Year of Older Persons campaign. Sydney: NSW Department of Health, 1999.

7. Singh NA, et al. A randomized controlled trial of progressive resistance training in depressed elders. J Gerontol A Biol Sci Med Sc 1997;52(1):M27-35.

8. Layne JE, Nelson ME. The effects of progressive resistance training on bone density: a review. Med Sci Sports Exerc 1999; 31(1): 25-30.

9. Pyka G et al. Muscle strength and fibre adaptations to a year long resistance training program in elderly men and women. J Gerontol 1994; 49(1): M22-7. ⿱: 